\title{
AS BASES DA PRESUNÇÃO DE INOCÊNCIA NO PROCESSO PENAL
}

\section{THE BASIS OF THE PRESUMPTION OF INNOCENCE IN CRIMINAL PROCEEDINGS}

\author{
Nangel Gomes Cardoso \\ Professor, Faculdade Alfa, Brasil \\ E-mail: nangelgomescardoso@hotmail.com
}

Recebido: 01/05/2020 - Aceito: 20/05/2020

\section{RESUMO}

A preocupação básica deste estudo é investigar as bases do princípio da presunção de inocência insculpido tanto na Constituição Federal de 1988 quanto em instrumentos internacionais de direitos humanos, como o Pacto Internacional de Direitos Civis e Políticos das Nações Unidas e a Convenção Americana sobre Direitos Humanos a fim de possibilitar uma reflexão acerca da decisão proferida pelo Supremo Tribunal Federal em Medida Cautelar nas ações diretas de constitucionalidade ํo 43 e 44, a qual autorizou a execução provisória da pena mesmo antes do trânsito em julgado da sentença penal condenatória. Conclui-se que a decisão do Supremo não passa de mera tentativa de dirimir a sensação de impunidade vivenciada pelo cidadão brasileiro e a morosidade judicial, violando a presunção de inocência do cidadão.

Palavras-chave: Presunção; Inocência; Liberdade; Direitos Humanos

\section{ABSTRACT}

The primary concern of this study is to investigate the foundations of the presumption of innocence principle embodied in both the 1988 Federal Constitution and international human rights instruments, such as the United Nations International Covenant on Civil and Political Rights and the American Convention on Human Rights. In order to allow a reflection on the decision issued by the Federal Supreme Court in Precautionary Measure in constitutional actions 43 and 44, which authorized the provisional execution of the sentence even before the final judgment of the condemnatory sentence. It concludes that the decision of the Supreme does not go through the attempt to direct the sense of impunity experienced by the Brazilian citizen and the judicial slowness, violating the presumption of innocence of the citizen.

Keywords: Presumption; Innocence; Freedom; Human rights. 


\section{INTRODUÇÃO}

O presente trabalho tem como tema a presunção de inocência e a sua observância diante do atual cenário jurídico pátrio.

Nesta perspectiva, a questão que norteará este trabalho:

- $\quad$ A análise da legalidade e legitimidade do princípio da presunção de inocência como regra de direitos humanos incorporada pelo ordenamento jurídico pátrio.

Não há como negar que a presunção de inocência se constitui como um direito profundamente relevante do cidadão na luta contra as arbitrariedades do Estado-Juiz e a sua finalidade não deve ser desvirtuada para garantir a outrem privilégios que a lei não contempla.

Com a decisão proferida pelo Supremo Tribunal Federal, no entanto, surge uma nova perspectiva de relativização do princípio da presunção de inocência, autorizando a execução provisória da pena antes mesmo do trânsito em julgado da sentença.

Neste contexto, o objetivo primordial deste estudo é, pois, investigar a base legal e convencional do princípio da presunção de inocência para aferir a plausibilidade da decisão do Supremo Tribunal Federal.

Para alcançar os objetivos propostos, utilizou-se como recurso metodológico, a pesquisa bibliográfica, realizada a partir da análise pormenorizada de materiais já publicados na literatura e artigos científicos divulgados no meio eletrônico.

O texto final foi fundamentado nas ideias e concepções de autores como: Batistti (2010) Eugênio Pacelli (2008), Talca (2005).

\section{REVISÃO BIBLIOGRÁFICA}

Em uma perspectiva meramente etimológica a palavra presunção adveio do 
latim praesumpt, onis ${ }^{1}$, e significa ideia antecipada, conjectura. Literalmente falando a presunção é um julgamento baseado em indícios, aparências que se tem por verdadeiras. Noutro vértice, inocência deriva do latim innocentia, $a e^{2}$ e designa brandura, mansidão.

A redação clássica do artigo $5^{\circ}$ LVII da Constituição Federal oferece uma ideia singela de presunção de inocência, asseverando que "ninguém será considerado culpado até o trânsito em julgado da sentença penal condenatória". Destarte, indispensável recorrer aos ensinamentos do Ministro do Supremo Tribunal Federal, Dias Toffoli para determinar que a presunção de nãoculpabilidade sempre esteve ligada à condição do acusado no processo criminal e sua origem conecta-se a alguns brocardos latinos, quais sejam:

(...) "na dúvida deve o juiz absolver o acusado" (in dubiis reus este absolvendus); "na dúvida, absolve" (in dubiis, abstine) e "na dúvida, sempre devem ser preferidas soluções mais benignas" (semper in dubiis benigniora praeferenda sunt,(...) D. 50.17.56).(Julgamento ADC 29 DF - Proferido no dia 15/02/2012. Publicação 27/02/2012)3.

Ainda em relação às considerações trazidas à baila pelo Ministro do Pretório Excelsior, convém ressaltar a importância da presunção de inocência nos instrumentos internacionais que também vislumbram a sua aplicabilidade, conforme se extrai dos excertos da fala do constitucionalista chileno Humberto Nogueira Alcalá, verbis:

"o direito à presunção de inocência constitui um estado jurídico de uma pessoa que se encontra imputada, devendo orientar a atuação do tribunal competente, independente e imparcial, preestabelecido por lei, enquanto tal presunção não se perca

\footnotetext{
1 Dicionário eletrônico Houaiss - Dicionário da língua portuguesa.

2 Dicionário eletrônico Houaiss - Dicionário da língua portuguesa.

3 Julgamento ADC 29 DF - Ministro Relator Dias Toffoli - Supremo Tribunal Federal - Proferido em 15/02/2012. Publicação 27/02/2012)
} 
ou destrua pela formação da conviç̧ão do órgão jurisdicional através da prova objetiva sobre a participação culposa do imputado ou acusado nos fatos constitutivos do delito, seja como autor, cúmplice ou acobertador, condenando-o por esse (delito) através de uma sentença firmemente fundada, congruente e ajustada às fontes do direito vigentes."(Consideraciones sobre el derecho fundamental a la presunción de inocencia. lus et Práxis, v.11, n.1, Talca 2005. Apud Julgamento ADC 29 DF - Relator Ministro Dias Toffoli Proferido no dia 15/02/2012. Publicação 27/02/2012).

Prosseguindo a explanação acerca do conceito de presunção de inocência com base no direito comparado, vale destacar a esclarecedora lição do espanhol Enrique Belda Pérez-Pedrero no sentido de que a não culpabilidade deve ser preservada "até o momento em que uma sentença, pronunciada por um tribunal legal e independente no âmbito de um processo no qual se conservam todas as garantias constitucionais, condena o processado em relação a um ou vários delitos concretos."

No direito brasileiro, seja na doutrina ou na jurisprudência, também é nítida a relevância atribuída ao princípio em questão. O Ministro do Supremo Tribunal Federal Celso de Mello pondera que "o princípio constitucional da presunção de inocência, em nosso sistema jurídico, consagra, além de outras relevantes consequências, uma regra de tratamento que impede o Poder Público de agir e de se comportar, em relação ao suspeito, ao indiciado, ao denunciado ou ao réu, como se estes já houvessem sido condenados, definitivamente, por sentença do Poder Judiciário. Precedentes."

Em uma perspectiva mais doutrinária, pode-se destacar no magistério do professor Eugênio Pacelli, a alegação de que o princípio da presunção de inocência

\footnotetext{
${ }^{4}$ PÉREZ-PEDRERO, Enrique Belda. La presunción de inocencia. Parlamento y Constitución. Anuario, no 5, 2001, p.179-204. p. 180. Apud Julgamento ADC 29 DF - Relator Ministro Dias Toffoli - Proferido no dia 15/02/2012. Publicação 27/02/2012
}

${ }^{5}$ HC 95.886, Relator Ministro Celso de Mello, Segunda Turma, DJe-228 4/12/2009. 
impõe ao Poder Público a observância de duas regras específicas em relação ao acusado, verbis:

"Uma de tratamento, segundo a qual o réu, em nenhum momento do iter persecutório, pode sofrer restrições pessoais fundadas exclusivamente na possibilidade de condenação, $e$ outra de fundo probatório, a estabelecer que todos os ônus da prova relativa à existência do fato e à sua autoria devem recair exclusivamente sobre a acusação". (OLIVEIRA, Eugênio Pacelli de. Curso de Processo Penal. Rio de Janeiro. Lumen Juris. p. 49).

Incumbe salientar que apesar das distinções na origem e na estrutura dos conceitos ora apresentados, em todos, a presunção de inocência revela a ideia de imposição, vinculação, observação compulsória pelo Estado-Juiz dos direitos fundamentais inerentes ao cidadão.

Noutro vértice, é nítida a menção à forma comportamental do Estado em relação ao acusado, vedando qualquer tipo de tratamento que suscite um préjulgamento. Apesar de parecer redundante, essa ressalva é de extrema importância, já que o Código de Processo Penal, embora tenha sofrido várias reformas com o decorrer do tempo, foi elaborado na década de 40 (quarenta), período em que não se vislumbrava o modelo garantista contemplado pela atual Carta da República.

Fincadas as bases do princípio da presunção de inocência no ordenamento pátrio, seja por intermédio da Constituição Federal, seja em decorrência da noção de bloco de constitucionalidade com a incorporação das regras decorrentes do Pacto Internacional de Direitos Políticos e Civis das Nações Unidas e da Convenção Americana sobre Direitos Humanos, resta refletir acerca da decisão proferida pelo Supremo Tribunal Federal.

Antes, porém, deve se mencionar que não é novidade que boa parte do problema vivenciado pela sociedade e pelo ordenamento jurídico em si passa fatalmente pela ineficiência do Poder Judiciário pátrio. Em um primeiro momento, o que de pronto se imagina como parcela de culpa do poder judiciário é a questão da morosidade da sua atuação, mas tal deficiência é fruto da desestruturação do órgão que não acompanhou a celeuma de direitos atribuídos ao cidadão brasileiro pela 
Constituição Federal de 1988 e, por isso, caminha a passos lentos para se tornar um órgão judicante típico de um país amplamente democrático.

A parcela de culpa que se quer ressaltar aqui é exatamente àquela relativa ao processo e à jurisdição brasileira que, embora contemple apenas dois graus, conta ainda com amplos recursos aos tribunais superiores e ao Supremo Tribunal Federal, o que apenas posterga a prolação de uma sentença definitiva e transforma a presunção de inocência em um escudo para a prática de outros mais delitos.

Uma alternativa proposta pelo Senador Ricardo Ferraço, PMDB/ES foi levada à apreciação em audiência pública por intermédio da PEC 15/11 e consiste em suprimir os recursos ao Superior Tribunal de Justiça e ao Supremo Tribunal Federal. Pela proposta de Emenda à Constituição, tanto o recurso especial (STJ) quanto o recurso extraordinário (STF) se transformariam em ações rescisórias a serem apreciadas pelos respectivos órgãos, a depender da matéria e não possuiriam efeito suspensivo em relação à decisão dos tribunais em âmbito de segundo grau de jurisdição. ${ }^{6}$

O diretor da escola de direito da Fundação Getúlio Vargas, Joaquim de Arnaldo Falcão já se manifestou favoravelmente à mudança, especialmente com base nos estudos realizados pela referida fundação, pois seria irracional a existência de quatro graus de jurisdição no Brasil com ampla previsão recursal. ${ }^{7}$

O estudo "supremo em números" analisou dados colhidos de 1988 a 2009 e concluiu que à época existiam 52 tipos de recursos possíveis para chegar ao Supremo, sendo que hoje este número foi reduzido à 37 , mas mesmo assim, este ainda é um número inédito em termos de direito comparado. Absolutamente não existe no mundo. Ainda a respeito da quantidade imensurável de processos recebidos pelo Supremo Tribunal Federal, o diretor da escola de direito da Fundação Getúlio Vargas assim ponderou, verbis:

No mesmo período, segundo ele, o Supremo recebeu mais de 1,2 milhão de processos. Desses, pouco mais de $6 \mathrm{mil}(0,51 \%)$ tratavam de temas de natureza

\footnotetext{
${ }^{6}$ AMMP Notícias - Órgão informativo da Associação Mineira do Ministério Público. Biênio 2010/2012. № 41. Outubro/Novembro 2011. Pág 11.

${ }^{7}$ AMMP Notícias - Órgão informativo da Associação Mineira do Ministério Público. Biênio 2010/2012. № 41. Outubro/Novembro 2011. Pág 11.
} 
constitucional, enquanto 95,3 mil se referiam a matéria ordinária de competência da corte. A absoluta maioria decorreu de recursos (mais de 1,1 milhão de processos ou 91,6\% desse total). Destes, observou, 96\% foram negados, tendo servido apenas para retardar a execução das sentenças. "Quantitativamente, portanto, o Supremo não é corte constitucional. Está mais para corte recursal suprema”, completou.

Noutro vértice, a superveniência e posterior reconhecimento de constitucionalidade da Lei Complementar no 135/2010 certamente influiu na decisão proferida pelo Supremo Tribunal Federal, sobretudo porque, atendendo aos clamores da sociedade brasileira, a condenação criminal em grau de recurso passou a ser considerada causa de inelegibilidade, mesmo antes do trânsito em julgado da sentença condenatória, o que já suscitou controvérsias acerca da aplicabilidade do princípio da presunção de inocência.

Na decisão proferida no julgamento das ADC's 43 e 44, o Supremo Tribunal Federal autorizou a execução da sentença criminal, mesmo que não haja trânsito em julgado, logo, optou por dirimir a morosidade judicial e a sensação de impunidade oriunda do poder público violando o direito fundamental à presunção de inocência.

\section{CONSIDERAÇÕES FINAIS}

Diante do exposto, concluiu-se que a decisão proferida pelo Supremo Tribunal Federal, não obstante fundamentada de acordo com o entendimento dos eminentes Ministros, não encontra respaldo no bloco de constitucionalidade incorporado pela República Federativa do Brasil, sobretudo porque as bases do princípio da presunção de inocência se encontram fincadas em instrumentos normativos sólidos, tanto de forma doméstica quanto em tratados internacionais, inexistindo espaço para a execução provisória de sentença penal condenatória antes do trânsito em julgado.

\section{REFERÊNCIAS}

AMMP Notícias - Órgão informativo da Associação Mineira do Ministério Público. Biênio 2010/2012. № 41. Outubro/Novembro 2011 
BATISTI, Leonir. Presunção de Inocência: a apreciação dogmática e nos instrumentos internacionais e Constitucionais do Brasil e Portugal. Londrina. Editora Juruá, 2009.

BRASIL. Constituição(1998). Constituição da República Federativa do Brasil. Brasília, DF: Senado Federal: Centro Gráfico 1988.

HOUAISS, Antônio: Dicionário da Língua Portuguesa. Ed. 1/2009. Editora Objetiva.

NERY JR, Nelson; Rosa Maria de Andrade / Constituição Federal Comentada e Legislação Federal Comentada. São Paulo. Editora Revista dos Tribunais. 2011.

$\mathrm{NUCCl}$, Guilherme de Souza. Código de Processo Penal Comentado. São Paulo. Editora. Revista dos Tribunais, 2009.

NUCCI, Guilherme de Souza. Manual de processo penal e execução penal. São Paulo: Editora Revista dos tribunais, 2010.

OLIVEIRA, Eugênio Pacelli de. Curso de Processo Penal. Rio de Janeiro. Ed. Lumen Juris. 2010.

PÉREZ-PEDRERO, Enrique Belda. La presunción de inocencia. Parlamento y Constitución. Cortes de Castilla-La Mancha. Anuario, no 5, 2001 
Revista Jurídica do Nordeste Mineiro, v 01, 2020/01 